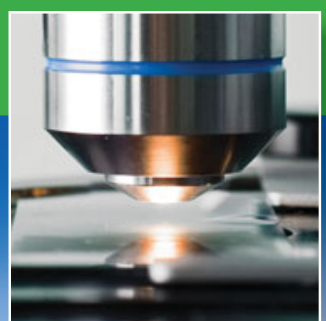

\title{
Measurements, standards, and data in support of the sustainable use of materials
}

\author{
Dianne L. Poster, Michael J. Fasolka, Richard R. Cavanagh, \\ and Ellyn S. Beary
}

Industry is increasingly aware that sustainability combines environmental, societal, and economic considerations in product development and that this linkage, while driving improved performance, can pose both a business opportunity and a challenge. On one hand, innovations make good business sense by bringing new products to supply a growing market demand for sustainable goods. On the other hand, new regulatory standards demand cleaner, less-toxic products, which can be difficult to develop economically, and require an agreed-upon infrastructure to demonstrate compliance, which can also be difficult and expensive. In this article, we discuss how measurements, standards, and data, being developed and deployed worldwide by national metrology institutes (NMIs) and standards-developing organizations (SDOs), are helping industry enable the sustainable use of materials. Examples include bio-based polymers, lightweight automobiles, fly-ash-based concrete, and lead-free solders. Measurements, standards, and data also support energy efficiency and renewable energy and ease industry compliance with new and emerging regulations, including those that demand less-toxic components.

\section{Introduction}

Sustainability is at the intersection of public, government, and private interests. Citizens around the world are seeking products and practices that support the sustainable use of materials, governments are enacting policies that promote it, and businesses wish to provide products and services that appeal to consumers and meet government regulations. How can any of these groups be assured that their efforts to support sustainability are effective? The answer is "standards." Standards enable the public, governments, and businesses to make progress and realize improved sustainability in a uniform manner. Three different types of standards typically come into play: regulatory standards, documentary standards, and measurement standards.

Regulatory standards enforce the provisions of legislation. They set requirements that industry and the public must follow, and they allow government agencies to enforce conformance with those requirements. For example, the U.S. Environmental Protection Agency (EPA) sets standards that define how much asbestos is allowed in specific chemical forms in a variety of products. In addition, under the Resource Conservation and Recovery Act (RCRA), EPA regulates household, industrial, and manufacturing solid waste. The RCRA in particular gives the EPA the authority to control hazardous waste "from cradle to grave" and includes the rules necessary for governing its generation, transportation, treatment, storage, and disposal. ${ }^{1}$

Documentary standards specify uniform technical criteria and methods to enable comparisons among products, processes, and test results. They are established by various standardsdeveloping organizations (SDOs). SDOs can be national or international in scope and draw on a broad range of technical expertise. Familiar examples include the International Organization for Standardization (ISO), the American National Standards Institute (ANSI), and ASTM International. Other organizations set documentary standards within more specialized contexts, such as the Society of Automotive Engineers (SAE) International, the Institute of Electrical and Electronics Engineers (IEEE), and the American Petroleum Institute (API). Documentary standards from these or other 
independent organizations can be incorporated by reference and become the basis for regulatory standards. For example, in November 2010, the U.S. Department of the Interior proposed to incorporate by reference 15 new production measurement industry standards into the regulations governing oil, gas, and sulfur operations in the Outer Continental Shelf. ${ }^{2}$

Measurement standards are typically physical artifacts that provide a common reference for a property of interest, but they can also be critically evaluated data or calibrations or wellcharacterized samples. The highest-level standards are traceable to the fundamental constants of the International System of Units. Examples include a specific form of asbestos, a diesel fuel of known composition, a steel bar of known strength, or a light source of known spectral composition. These standards allow instruments to be calibrated and measurements to be made that, when required, can be traced back to fundamental constants with a known uncertainty. Figure 1 shows examples of reference materials produced by a variety of national metrology institutes (NMIs).

This article describes measurements, standards, and datadevelopment activities being conducted by the National Institute of Standards and Technology (NIST), other NMIs, and SDOs around the world to support the sustainable use of materials. In some cases, these standards are fully developed, whereas in others, SDOs and NMIs are performing research to support the development of both documentary and measurement standards.

\section{Measurements, standards, and data in support of materials substitution}

Materials substitution is a key strategy for manufacturers to improve the performance and lower the cost of products. Substitution can also foster sustainability, for example, if the original material is toxic or nonrenewable or if its production results in significant greenhouse-gas (GHG) emissions, energy use, or byproducts that are potentially hazardous. Substantial challenges to materials substitution include reformulating/redesigning products, determining feedstock manufacturability and quality-control metrics, and establishing long-term reliability.

\section{Lowering barriers to the use of bio-based feedstocks for polymer products}

Using more bio-based feedstocks in the manufacture of polymeric products has several advantages, including increasing the use of renewable plant-based sources and decreasing the dependence on the volatile oil market, while meeting increasing consumer demand. Many bio-based polymer materials are also biodegradable and could thus dramatically reduce the amount of plastics-based solid waste. A 2009 analysis showed that biobased polymers could provide technically suitable replacements for nearly $90 \%$ of petroleum-based plastics. ${ }^{7}$ However, if these potential applications of bio-based polymers are to be realized, proper data sets, quality-control systems, and manufacturing infrastructure must be built. A number of life-cycle assessments (LCAs) have demonstrated a significant net reduction in GHG emissions and fossil energy consumption in the case of bio-based replacements for fossil energy sources. ${ }^{8}$ However, in the case of bio-based polymer products, a recent study demonstrated that LCAs of these complex systems can be highly sensitive to the type and quality of materials data employed, which can lead to conflicting conclusions about environmental impacts, such as GHG emissions and energy consumption. ${ }^{9}$

To validate environmental claims about their products, polymer manufacturers need reliable measures of the biobased content in their feedstocks, which can also contain petroleum-based sources. The accepted measure of bio-based content is the level of ${ }^{14} \mathrm{C}$ isotope in the feedstock (basically, carbon dating), because ancient petroleum has lost its ${ }^{14} \mathrm{C}$ through radioactive decay whereas feedstocks derived from recently living organisms have a ${ }^{14} \mathrm{C}$ content related to the current equilibrium concentration in the atmosphere. ASTM has developed a protocol to quantify the bio-based content in materials by comparing the ${ }^{14} \mathrm{C} /{ }^{12} \mathrm{C}$ ratio to that of a standard specimen typical of living organisms. ${ }^{10}$
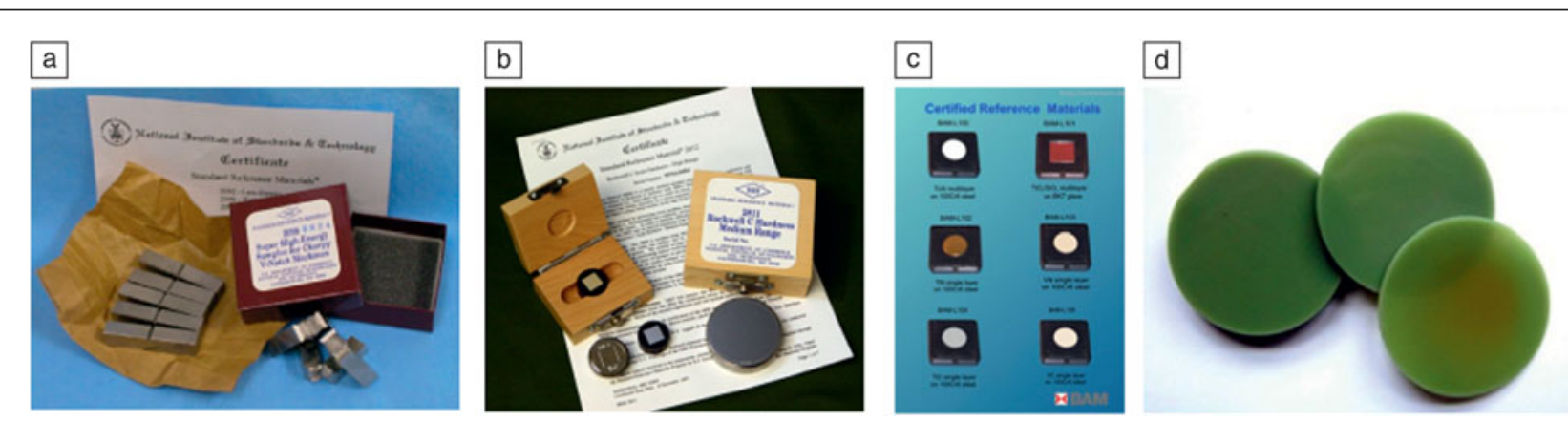

Figure 1. Reference materials, used to calibrate measurement instrumentation, come in many forms, from bulk metal artifacts to powders and films: (a,b) U.S. National Institute of Standards and Technology standard reference materials for calibrating (a) impact fracture ${ }^{3}$ and (b) hardness ${ }^{4}$ measurements. (c) Certified reference materials from Germany's Federal Institute for Materials Research and Testing (BAM) ${ }^{5}$ for calibrating the depth resolution of surface chemical analysis techniques, consisting of both single-layer and multilayered coatings of metals and oxides. (d) Another reference material from BAM ${ }^{6}$ for use in quality assurance, especially for measuring trace elements in polymers and related matrices. 
Measurement protocols have also been established to assess the biodegradability of bio-based polymers in various environments. For example, ASTM D5526 and a related set of documentary standards detail test methods to measure biodegradation of polymers under a variety of environments, including landfills and compost systems. ${ }^{11}$ The European Union has developed similar documentary standards for labeling a polymer product as biodegradable. ${ }^{12}$ These standard specifications and test methods validate claims made about bio-based products, thereby increasing consumers' confidence in such products.

\section{Automotive lightweighting}

Lighter cars are more fuel-efficient, resulting in lower emissions and fuel consumption. ${ }^{13}$ The auto industry is moving to replace traditional die-pressed sheet steels with new lightweight alloys (specifically, aluminum alloys, magnesium alloys, and high-strength steels) to help meet emerging fuel-economy regulations. However, the forming equipment, processes, and models used by the auto industry were designed for traditional die-pressed sheet steels. Material data, models, and standard tests are helping industry achieve its lightweighting goals. ${ }^{14}$ For example, in contrast to current industry design practice, which limits the maximum strain during forming, a more useful measure for the new materials is the stress. In response, NIST has leveraged an ASTM springback test ${ }^{15}$ and outfitted forming equipment with x-ray-based instrumentation to measure stresses in sheets as they are shaped under actual manufacturing conditions. ${ }^{16}$ This work has provided time-saving measurement data and predictive models to automotive manufacturers and associations including Ford, General Motors, Volvo, and the United States Council for Automotive Research, as well as sheet metal manufactures such as Alcoa and U.S. Steel.

ASTM has a number of documentary standards relevant to lightweighting, for example, for radiographic inspection of magnesium castings. ${ }^{17}$ In principle, such standards could ensure the quality of engine blocks and other components cast from lightweight magnesium alloys, although one study suggests that these standards must be updated to be useful for automotive parts. ${ }^{18}$ The European Council for Automotive Research and Development highlighted the needs for lightweight composite, alloy, and hybrid materials in a 2011 position paper focusing on materials replacements in automotive interiors. ${ }^{19}$ Japan's National Institute for Materials Science has also highlighted automotive lightweighting, but has not yet issued standards. ${ }^{20}$ Indeed, the U.S. Department of Energy (DOE) Vehicle Technology Program Materials Research Roadmap, updated in 2010, suggests the need for at least five additional years of fundamental research for many substitute materials classes. ${ }^{21}$

\section{Reuse of fly ash for concrete production}

Fly ash is a well-suited replacement for siliceous and calcareous components of concrete when it has the correct composition and particulate properties. However, fly ash varies dramatically in composition depending on the quality of the coal from which it is derived and its combustion conditions, which complicates its use as a substitute feedstock. In part to meet this challenge, the U.S. EPA has issued guidelines on the levels of fly ash that can be used in concrete applications. ${ }^{22}$ In addition, ASTM has provided key quality-control measures by defining standard procedures for sampling and testing fly ash and has classified fly-ash feedstocks based on general ranges of composition, related mainly to the type of coal from which they are derived. Existing standards enable industry to reliably assess fly-ash feedstocks for their suitability in concrete. Ongoing measurement research in the United States and Europe targets guidelines and standards to support the even higher volume fractions of fly ash. NIST aims to establish measurement protocols (Figure 2) and models to better predict the short-term setting of high-volume-fly-ash cement binder formulations. ${ }^{23}$ Similar efforts to measure structure-propertyperformance relationships in fly-ash cement are underway in Europe. For example, Germany's Federal Institute for Materials Research and Testing is characterizing enhanced chemical degradation that has been observed in fly-ash cements to provide guidelines for formulations that would avoid this failure mode. ${ }^{24}$

In coming years, the levels of toxics will become increasingly important in measurement and standards research on

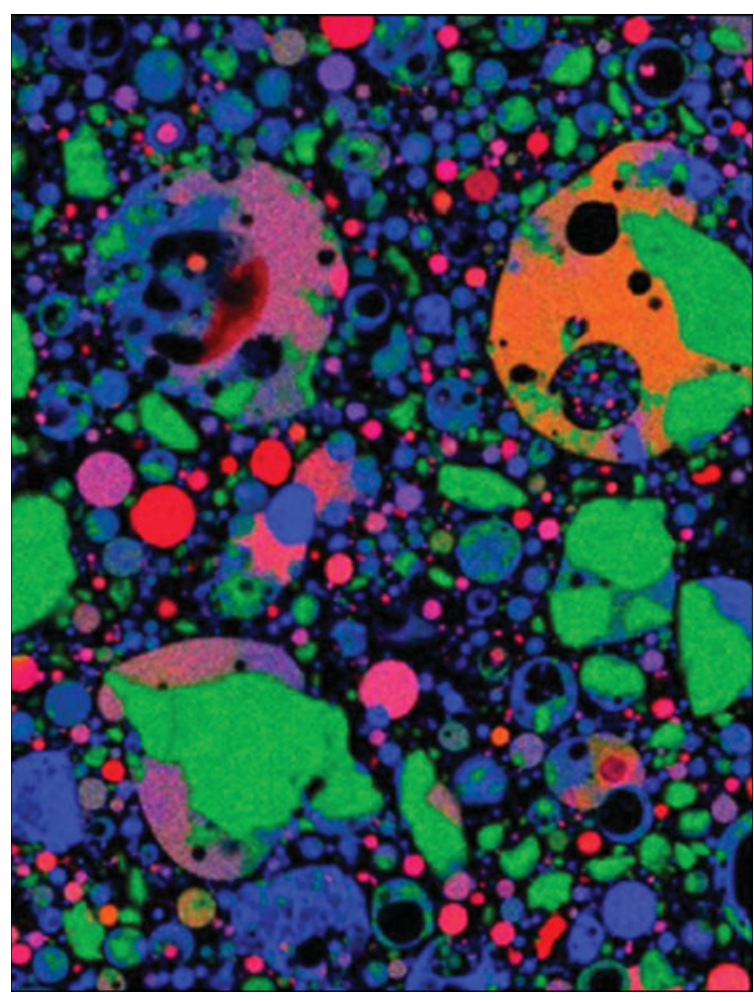

Figure 2. Scanning electron microscopy $x$-ray image $(150 \mu \mathrm{m} \times 133 \mu \mathrm{m})$ showing spatial distributions of calcium (red), silicon (green), and aluminum (blue) in coal fly-ash material. Such measurement techniques and data will help industry accommodate fluctuations in fly-ash feedstock composition that can lead to unacceptably long setting times and other degradations in binder performance when fly ash is used in high volumes. (Credit: Paul Stutzman, National Institute of Standards and Technology.) 
fly-ash-laden cements. For example, the European Union is developing revisions to standards and policy that would reclassify fly ash as a "waste product" rather than a "byproduct," 25 thereby making fly ash susceptible to the stringent REACH (Registration, Evaluation, Authorisation and Restriction of Chemical substances) ${ }^{26}$ and RoHS (Restriction of the Use of Certain Hazardous Substances in Electrical and Electronic Equipment) ${ }^{27}$ regulations. New regulations are being considered in the United States as well. ${ }^{28}$ Standard protocols that quantify levels of toxics in fly ash will be needed to support industry compliance with these and related laws. Control technologies designed to reduce air pollution from power plants could shift pollutants from the flue gas to fly ash and other airpollution-control residues. The potential reuse of these materials raises concerns about the release of sequestered mercury during processing and the presence of toxics in the finished products. These issues warrant extensive characterizations of coal combustion residues, ${ }^{29}$ as well as the development of Standard Reference Materials (SRMs) consisting of these byproducts. ${ }^{30}$

\section{Properties and reliability of lead-free solders and finishes}

Driven in part by RoHS and the WEEE (Waste Electrical and Electronic Equipment) Directive ${ }^{31}$ in Europe and similar trends in Japan, electronics manufactures have transitioned to the use of lead-free solders in their products. Several lead-free solder materials are available, mainly $\mathrm{Sn}-\mathrm{Ag}-\mathrm{Cu}, \mathrm{Ag}-\mathrm{Cu}$, and $\mathrm{Sn}-\mathrm{Cu}$ alloys, but their full implementation in manufacturing is hindered by a lack of data supporting their quality control, processing limits, and long-term reliability. Accordingly, SDOs and NMIs have been developing measurements, data, and standards to support use of the most promising replacement materials. For example, to provide a reference for the compositional analysis of leadfree solder alloys, Japan's Society for Analytical Chemistry has produced a series of certified reference materials (JSAC 0131JSAC 0134) $)^{32}$ for $\mathrm{Sn}-\mathrm{Ag}-\mathrm{Cu}$ solders, and NIST has deployed SRM $1728^{33}$ (Figure 3). In turn, measurement techniques, such as protocols for quantifying trace-element content using $\mathrm{X}$-ray fluorescence spectrometry methods, ensure that lead-free products comply with regulatory and reporting thresholds. ${ }^{34}$

Driven by COST (European Cooperation in Science and Technology) Action $531^{35}$ on lead-free solder materials, databases of solder thermodynamic and physical properties have been compiled. For example, the National Physical Laboratory (NPL), the UK's NMI, has established a public database of critically evaluated thermodynamic parameters for over 50 binary alloys and numerous ternary systems of eleven elements that can potentially be used in lead-free solder formulations. ${ }^{36}$ The Polish Academy of Sciences compiled the downloadable SURDAT database, ${ }^{37}$ which lists experimentally determined molar volumes, densities, and surface tensions of $\mathrm{Ag}-\mathrm{Cu}$ and $\mathrm{Sn}-\mathrm{Ag}-\mathrm{Cu}$ systems. In addition, the Japanese Standards Association has established test methods for determining critical physical and engineering properties of lead-free solders (JIS Z 3198-1-JIS Z 3198-7).

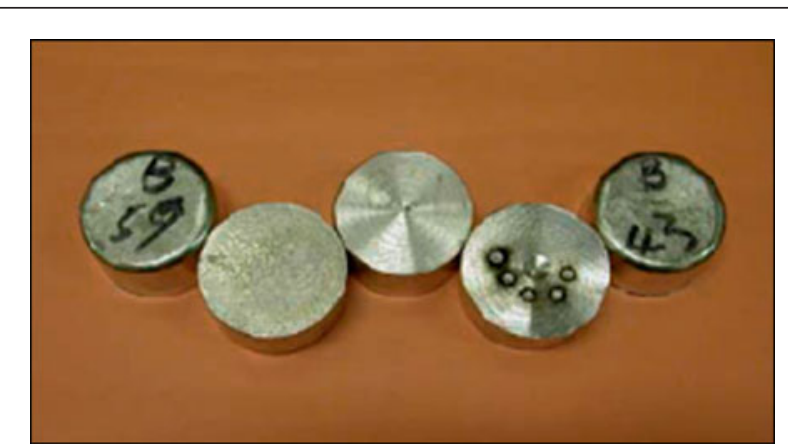

Figure 3. Disks of Standard Reference Material (SRM) 1728 Tin Alloy (Sn-3Cu-0.5Ag), a lead-free solder composition, showing various stages in manufacturing and testing. The alloy was created using a semi-chill casting process to ensure homogeneity of the disks to a depth of at least $10 \mathrm{~mm}$. The SRM provides values for bulk composition of a number of elements, including chromium, cadmium, mercury, and lead, which are restricted in products around the world for environmental and health reasons. ${ }^{33}$

Lead-free solders and finishes have been employed in some electronics applications for nearly 70 years, but the tremendous increase in their use over the past decade has brought attention to some ways in which these materials can fail. ${ }^{38}$ In particular, over long periods, normally stable solder balls and interconnects can develop structural and morphological changes that result in the formation of cracks, pull-offs, and "whiskers"-microscopic, hair-like protrusions of metal, sometimes centimeters long - that can cause short circuits in devices (Figure 4). Such failures are problematic for long-lifetime components, such as those found in mainframe computers, and can be catastrophic in critical

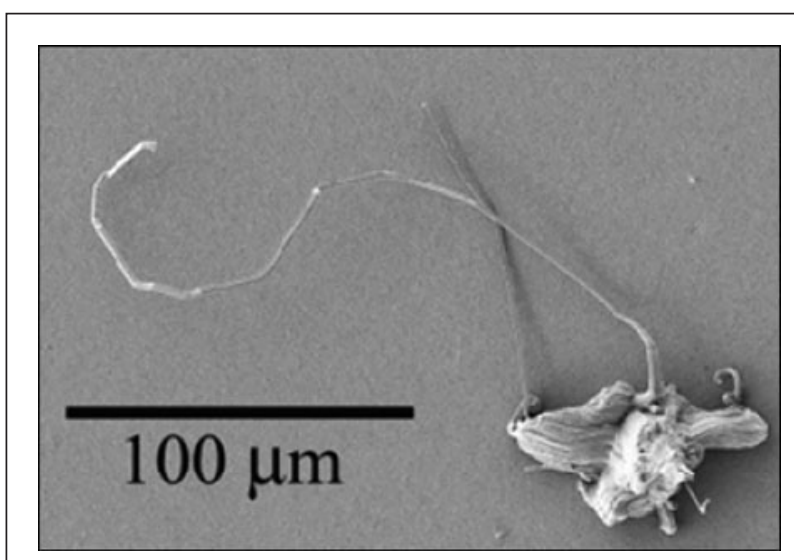

Figure 4. Scanning electron microscopy image of a tin whisker growing from a lead-free surface finish. ${ }^{39}$ The composition of the lead-free surface finish is tin with $3 \%$ mass fraction copper (Sn-3 wt\% Cu). The whisker growing out of the surface finish is tin. Tin whiskers often grow spontaneously from pure tin electrodeposits and short-circuit finely pitched electrical components. Adding a low percentage of lead inhibits whisker growth, but environmental concerns have resulted in a demand for lead-free finishes and whisker-mitigation strategies. (Credit: Maureen Williams, National Institute of Standards and Technology.) 
applications such as aircraft and medical devices. For example, according to the U.S. National Aeronautics and Space Administration, since 1992, at least four in-orbit satellites have lost full function as a result of the formation of tin whiskers from lead-free solders and finishes, and another four have partially lost function. ${ }^{40}$

Roadmaps by the International Electronics Manufacturing Initiative (iNEMI) have highlighted the reliability and failure mechanisms of lead-free solders as priority issues to address, leading to the establishment of a working group to produce accelerated test methods for measuring tin whisker growth. ${ }^{41,42}$ This work has enabled industry users and producers of lead-free finishes to assess the rate at which tin whiskers can form and grow from these materials under service conditions. NIST has also assessed the conditions of tin-whisker growth, ${ }^{43}$ demonstrating that whiskers grow only when column-shaped grains form perpendicular to the finish surfaces ${ }^{44}$ and that whisker growth releases residual stress in the material.

\section{Energy efficiency and renewable energy Tuning the color of solid-state lighting}

Solid-state lighting (SSL), historically limited to monochromatic light-emitting diodes (LEDs), became viable for broad consumer and commercial applications with the advent in 1997 of LED-driven devices that produce white light by incorporating phosphors. However, consumer acceptance of SSL depends on whether it can emit the "warmer" white tones of incandescent bulbs. Blue-tinged "bright-white" sources have a "cold" quality that many people find unpleasant. The color tone of the light from SSL devices can be controlled by tuning the phosphor materials, but developing, choosing, and processing these materials in ways that achieve consistent performance can be challenging. Standards help SSL manufacturers meet these challenges, by enabling them to tune the emission of phosphor mixtures and to gauge the performance of candidate phosphor and LED materials $^{45}$ (Table I).

\begin{tabular}{|c|c|c|c|}
\hline Standard and title & Developer(s) & Description & Year of publication \\
\hline CIE 127:2007 Measurement of LEDs & CIE, NIST 46 & $\begin{array}{l}\text { Provides recommendations on how to measure } \\
\text { the luminous/radiant intensity, total and } \\
\text { partial flux, and spectral power distribution; } \\
\text { requires standard LEDs to be calibrated } \\
\text { by National Metrology Laboratories or a } \\
\text { laboratory traceable to National Metrology } \\
\text { Laboratories }^{47}\end{array}$ & 2007 \\
\hline $\begin{array}{l}\text { IESNA LM-79 Electrical and Photometric } \\
\text { Measurements of Solid-State Lighting } \\
\text { Products }\end{array}$ & $\begin{array}{l}\text { ANSI, IESNA, CIE, } \\
\text { U.S. DOE, NIST }\end{array}$ & $\begin{array}{l}\text { Requires complete luminaire testing and } \\
\text { describes the methods for testing SSL } \\
\text { products for their light output (lumens), } \\
\text { energy efficiency (lumens per watt), } \\
\text { and chromaticity }{ }^{48}\end{array}$ & 2008 \\
\hline $\begin{array}{l}\text { IESNA LM-80 Measuring Lumen } \\
\text { Maintenance of LED Light Sources }\end{array}$ & $\begin{array}{l}\text { IESNA with collaborations } \\
\text { as above }\end{array}$ & $\begin{array}{l}\text { Provides for reliable comparisons of test results } \\
\text { among laboratories by establishing uniform } \\
\text { test methods; addresses the measurement } \\
\text { of lumen maintenance testing for LED light } \\
\text { sources including LED packages, arrays, and } \\
\text { modules }^{49}\end{array}$ & 2008 \\
\hline $\begin{array}{l}\text { C78.377-2008 American National Standard } \\
\text { for Electric Lamps-Specifications for } \\
\text { the Chromaticity of Solid State Lighting } \\
\text { (SSL) Products }\end{array}$ & ANSI, NEMA, ANSLG, NIST & $\begin{array}{l}\text { Specifies the recommended color ranges } \\
\text { for SSL products using cool to warm } \\
\text { white LEDs with various correlated color } \\
\text { temperatures; } 50 \text { applies to LED-based SSL } \\
\text { products with control electronics and heat } \\
\text { sinks incorporated and covers fixtures } \\
\text { incorporating light sources as well as } \\
\text { integrated LED lamps }\end{array}$ & 2008 \\
\hline $\begin{array}{l}\text { NEMA SSL 3-2011 High-Power White LED } \\
\text { Binning for General Illumination }\end{array}$ & NEMA & $\begin{array}{l}\text { Offers categorization areas (bins) for } \\
\text { chromaticity (colors), forward voltage } \\
\text { measurements (an electrical designation), } \\
\text { and luminous flux (light output) for LEDs } \\
\text { used for general lighting }\end{array}$ & 2011 \\
\hline $\begin{array}{l}\text { CIE TC 1-69 Colour Rendition of White } \\
\text { Light Sources }\end{array}$ & CIE, NIST & $\begin{array}{l}\text { Addresses problems with the CIE Color } \\
\text { Rendering Index for SSL sources and } \\
\text { meets the new priority needs of the lighting } \\
\text { industry and consumers for communicating } \\
\text { color quality of lighting products }\end{array}$ & In progress \\
\hline
\end{tabular}

Acronyms: ANSI, American National Standards Institute; ANSLG, American National Standard Lighting Group; CIE, International Commission on IIlumination; IESNA, Illuminating Engineering Society of North America; LED, light-emitting diode; NEMA, National Electrical Manufacturers Association; NIST, National Institute of Standards and Technology; SSL, solid-state lighting; U.S. DOE, U.S. Department of Energy. 
The development of SSL standards is part of the U.S. government's effort to help the DOE reach its goal of developing and introducing SSL to reduce energy consumption for lighting by $50 \%$ by 2025 and to support the ENERGY STAR program, a joint program of the DOE and the EPA that promotes energy-efficient products and practices. NIST independently tested 150 ENERGY STAR-qualified products, using measurement methods traceable to national electrical standards, and confirmed that these products met EPA product specifications (100\% for digital versatile disc products and computer monitors and $95 \%$ for printers). ${ }^{52}$

\section{Photovoltaics}

In its 2010 Technology Roadmap for Solar Photovoltaic Energy, the International Energy Association (IEA) indicated that, since 2000, global photovoltaic (PV) capacity has been increasing by more than $40 \%$ per year, on average, and has significant potential for long-term growth in coming decades. The IEA envisions that, by 2050 , photovoltaics will provide $11 \%$ of global electricity production (4500 TWh per year). Achieving such growth, however, necessitates policies in the next decade that enable optimal technology progress, cost reduction, and an increase of industrial manufacturing. ${ }^{53}$

One approach offering the possibility of greatly reduced manufacturing cost compared to conventional inorganic semiconductor silicon technology is organic photovoltaics (OPV). These are solar cells that use organic molecules, including polymers, dendrimers, small molecules, and dyes. However, OPV devices have much lower efficiencies than those based on traditional PV materials. To provide design principles for optimizing OPV materials and devices, a suite of measurements aimed at determining the molecular and microstructural mechanisms of charge transport in these materials, especially across the complex interfaces within them, is being developed by NIST. Photoelectron spectroscopies, scanningprobe methods, and theoretical models of multiscale processes in thin organic films and polymeric heterojunctions are central to this pursuit. ${ }^{54}$ In addition to accelerating research, these measurement techniques could establish standard test methods for use by industry. Such methods for OPV and other organic electronic devices are being pursued through the Versailles Project on Advanced Materials and Standards (VAMAS), which includes efforts to develop reference methods and data to support the process optimization, quality control, and reliability of OPV devices. This effort is led by the VAMAS Organic Electronics Technical Working Area and is co-chaired by two NMIs: NPL and NIST. ${ }^{55}$

\section{Compliance with existing and emerging regulations}

In the mid-2000s, the European Union passed a series of "green directives" to reduce the levels of known hazardous substances in the environment. Implemented in February 2003 and updated in 2008, WEEE legislation restricts the use of hazardous substances in electrical and electronic equipment and promotes end-of-life collection and recycling of such equipment through electronic-waste collection schemes that are free of charge to the consumer. Another directive, REACH, is the
European Community regulation on chemicals and their safe use (EC 1907/2006) and requires that the chemical industry provide safety information on all substances that its members produce. Product manufacturers are required to gather the relevant information and register it into a central database ${ }^{56}$ run by the European Chemicals Agency. The agency manages, operates, and evaluates data submitted by manufacturers and importers on the chemicals used in their products.

Perhaps more directly impacting materials development is the RoHS legislation, enacted in 2006 and updated in 2011. This directive has been widely implemented and has led to similar legislation from individual U.S. states and countries such as Japan and China. The WEEE and RoHS regulations are related, in that the WEEE Directive focuses on the design and recycling of electronic products whereas RoHS aims to reduce the amount of hazardous substances used in electronics manufacture. In the updated standard, the maximum allowable levels remain the same, but they now apply to toys, leisure and sports equipment, medical devices, industrial monitoring and control instruments, and selected electrical and electronic equipment that had been excluded from the original directive. The newly included equipment will be phased in through 2019.57

International metrology institutes, including NIST, the Institute for Reference Materials and Measurements (IRMM) in Europe, and the National Institute of Metrology in China, have been working together to value assign new relevant certified reference materials. Two certified reference materials for the determination of various polybrominated diphenyl ethers (PBDEs) and decabrominated biphenyl in polymers are available from IRMM. ${ }^{58}$ Total bromine and total antimony are also characterized in these polymer reference materials, as the measurement of bromine or antimony can be used as a screening method for brominated flame retardants. In addition to SRM 1728 Tin Alloy ( $\mathrm{Sn}-3 \mathrm{Cu}-0.5 \mathrm{Ag}$ ) mentioned earlier (Figure 3), SRM 1124 Free-Cutting Brass has been developed by NIST ${ }^{59}$ Both of these materials contain known concentrations of restricted substances. Two solution SRMs have also been developed to address measurement issues related to PBDEs, and there are also new SRMs for lead in paint and phthalates in poly(vinyl chloride).

A large set of documentary and regulatory standards related to sustainability, including the ISO 14000 family, REACH, RoHS, and others, has been analyzed, and the consolidated information is available through a web portal. ${ }^{60}$ This effort has led to a framework for evaluating sustainability standards ${ }^{61,62}$ and offers a tool for determining what to measure, how to measure it, and how to report and validate the results. Similarly, for the electronics industries, the iNEMI, Association Connecting Electronics Industries (IPC), and NIST have developed a standard reporting format for manufacturers to exchange material content information between supply-chain participants. This work includes the development of a data management tool to address regulations beyond RoHS ${ }^{63}$

\section{Summary}

In all technological areas, the drivers for measurements and measurement standards are diverse. Standards are often 
required so that industry can ensure compliance with regulation. In the area of sustainable materials, REACH, RoHS, and other regulations have certainly spurred the development of replacement materials that contain fewer toxic substances. However, as discussed in this article for bio-based polymers, lead-free solders and finishes, and other applications, measurements and standards are not just reactive measures for regulatory compliance, but are also drivers for technological innovation. These tools clarify performance targets, as discussed for solid-state lighting. They can also substantiate claims of the environmental benefits of a product and thus attract customers for more sustainable goods, as described for bio-based polymers. Finally, measurement science, protocols, and standards support innovative research and development, as discussed for automotive weight reduction. Indeed, for sustainable materials research, such measurement solutions are especially important, because discovering, developing, and optimizing materials replacements depends strongly on the ability to determine their composition and structure and the properties that make them useful, less energy-intensive, less toxic, and renewable.

Disclaimer: Certain commercial entities are mentioned in this article. This does not imply recommendation or endorsement of these entities by the National Institute of Standards and Technology.

\section{References}

1. Summary of the Resource Conservation and Recovery Act. 42 U.S.C. $\S 6901$ et seq. (1976) (U.S. Environmental Protection Agency, Washington, DC, 2011), www.epa.gov/regulations/laws/rcra.html (accessed January 2012).

2. "Production Measurement Documents Incorporated by Reference," Fed. Regist. 75 (227), 72761-72766 (2010).

3. "Charpy Program" (National Institute of Standards and Technology, Gaithersburg, MD, 2011), www.nist.gov/mml/materials_reliability/structural materials/charpy-verification-program.cfm (accessed January 2012).

4. "Hardness Standard Reference Materials" (National Institute of Standards and Technology, Gaithersburg, MD, 2010), www.nist.gov/mml/metallurgy/materials_ performance/hardness_srms.cfm (accessed January 2012).

5. "Reference materials: Materials to calibrate GDOES depth profiles" (Federal Institute for Materials Research and Testing, Berlin, Germany, 2011), www. bam.de/en/kompetenzen/fachabteilungen/abteilung_6/fg64/fg64_ag1d.htm (accessed January 2012)

6. New Plastic Reference Material BAM-H010 (Federal Institute for Materials Research and Testing, Berlin, Germany, 2010).

7. L. Shen, J. Haufe, M.K. Patel, Product overview and market projection of emerging bio-based plastics. PRO-BIP 2009 (Utrecht University, Utrecht, The Netherlands, 2009).

8. F. Cherubini, A.H. Strømman, Bioresour. Technol. 102 (2), 437 (2011).

9. M.D. Tabone, J.J. Cregg, E.J. Beckman, A.E. Landis. Environ. Sci. Technol. 44 (21), 8264 (2010).

10. ASTM D6866-11. Standard Test Methods for Determining the Biobased Content of Solid, Liquid, and Gaseous Samples Using Radiocarbon Analysis (ASTM International, West Conshohocken, PA, 2011).

11. ASTM D5526-94(2011)e1. Standard Test Method for Determining Anaerobic Biodegradation of Plastic Materials Under Accelerated Landfill Conditions (ASTM International, West Conshohocken, PA, 2011).

12. BS EN 13432:2000. Packaging. Requirements for packaging recoverable through composting and biodegradation. Test scheme and evaluation criteria for the final acceptance of packaging (British Standards Institution, London, UK, 2000).

13. FY 2009 Progress Report for Lightweighting Materials (U.S. Department of Energy, Washington, DC, 2010).

14. "NIST Center for Metal Forming" (National Institute of Standards and Technology, Gaithersburg, MD, 2010), www.nist.gov/mml/metallurgy/materials_ performance/sheet_metal_forming.cfm (accessed January 2012).
15. ASTM E2492-07. Standard Test Method for Evaluating Springback of Sheet Metal Using the Demeri Split Ring Test (ASTM International, West Conshohocken, PA, 2007).

16. M.A. Iadicola, T. Foecke, S.W. Banovic, Int. J. Plast. 24, 2084 (2008).

17. ASTM E155-10. Standard Reference Radiographs for Inspection of Aluminum and Magnesium Castings (ASTM International, West Conshohocken PA, 2010).

18. S. Das, J.H. Peretz, B.E. Tonn, Automotive Lightweighting Materials Benefit Evaluation (Report ORNL/TM-2006/545, Oak Ridge National Laboratory, Oak Ridge, TN, 2006)

19. Challenges and Priorities for Automotive $R \& D$ (European Council for Automotive R\&D, Brussels, Belgium, May 2011).

20. J. Rosalie, Materials Engineering: An Introduction (National Institute for Materials Science, Tokyo, Japan, 2008).

21. FreedomCAR and Fuel Partnership: Materials Technology Roadmap (U.S. Department of Energy, Washington, DC, 2010).

22. "Cement and Concrete Specifications" (U.S. Environmental Protection Agency, Washington, DC, 2008), www.epa.gov/osw/conserve/tools/cpg/products/ cemspecs.htm (accessed January 2012).

23. Hydration of Concrete-Making Materials Containing High Volumes of Fly Ash (National Institute of Standards and Technology, Gaithersburg, MD, 2011).

24. "Damage Mechanisms and Protective Measures: Degradation of Concrete by Alkali Silica Reaction" (Federal Institute for Materials Research and Testing, Berlin, Germany, 2011), www.bam.de/en/kompetenzen/fachabteilungen/abteilung_7/ fg71/fg71_ag2c.htm (accessed January 2012).

25. H. Feuerborn, paper presented at the World of Coal Ash Conference (sponsored by the American Coal Ash Association and the University of Kentucky's Center for Applied Energy Research), Denver, C0, 9-12 May 2011. 26. "REACH" (European Commission-Environment, Brussels, Belgium, 2011), ec.europa.eu/environment/chemicals/reach/reach_intro.htm (accessed January 2012). 27. "What is RoHS?" (National Measurement Office, Teddington, UK), www.bis. gov.uk/nmo/enforcement/rohs-home (accessed January 2012).

28. "Coal Combustion Residuals—Proposed Rule" (U.S. Environmental Protection Agency,Washington,DC,2011), www.epa.gov/osw/nonhaz/industrial/special/fossil/ ccr-rule/index.htm (accessed January 2012).

29. D. Kosson, F. Sanchez, P. Kariher, L.H. Turner, R. Delapp, P. Seignette, Characterization of Coal Combustion Residues from Electric Utilities-Leaching and Characterization Data (Report EPA-600/R-09/151, U.S. Environmental Protection Agency, Washington, DC, 2009).

30. "Activated Carbon and FGD Gypsum Standard Reference Materials" (National Institute of Standards and Technology, Gaithersburg, MD, 2011), www.nist.gov/ mml/analytical/inorganic/fgdgypsum.cfm (accessed January 2012).

31. "Waste Electrical and Electronic Equipment (WEEE)" (Environment Agency, Rotterham, UK, 2011), www.environment-agency.gov.uk/business/topics/waste /32084.aspx (accessed January 2012).

32. J. Noro, T. Korenaga, M. Kozaki, S. Kawada, K. Kurusu, M. Mizuhira, A. Ono, K. Katsumi, K. Kakita, K. Takimoto, M. Sakata, Bunseki Kagaku 59 (2), 107 (2010)

33. "NIST SRM 1728 Tin Alloy (Sn-3Cu-0.5Ag) Supports Testing of LeadFree Solder," in SRM Spotlight (National Institute of Standards and Technology, Gaithersburg,MD, March 2011), www.nist.gov/srm/upload/March-2011-Spotlight-3. pdf (accessed January 2012).

34. J.R. Sieber, in Advances in X-ray Analysis: Proceedings of the Denver X-ray Conference (International Centre for Diffraction Data, Newton Square, PA, 2002), vol. 45, pp. 493-504.

35. "MPNS COST Action 531. Lead-free Solder Materials" (European Cooperation in Science and Technology, Brussels, Belgium, 2011), www.cost.esf.org/domains_ actions/mpns/Actions/531 (accessed January 2012).

36. "MTDATA: Phase Diagram Software from the National Physical Laboratory" (National Physical Laboratory, Teddington, UK, 2010), www.npl.co.uk/sciencetechnology/advanced-materials/measurement-techniques/mtdata (accessed January 2012).

37. "SURDAT Database of Lead-Free Soldering Materials" (Polish Academy of Sciences, Krakow, Poland, 2007), www.imim.pl/surdat-database (accessed January 2012).

38. G.T. Galyon, paper presented at the SMTAI Conference (sponsored by the Surface Mount Technology Association), Chicago, IL, 26-30 September 2004. 39. "Lead-Free Surface Finishes for Electronic Components: Tin Whisker Growth" (National Institute of Standards and Technology, Gaithersburg, MD, 2010), www.nist.gov/mml/metallurgy/thermodynamics_kinetics/lead-free_surface finishes.cfm (accessed January 2012).

40. "NASA Whisker Failures" (National Aeronautics and Space Administration, Washington, DC, 2009), nepp.nasa.gov/whisker/failures/index.htm (accessed January 2012).

41. "Roadmap" (International Electronics Manufacturing Initiative, Herndon, VA, 1998), www.nemi.org/cms/roadmapping/impact.html (accessed January 2012).

42. "Measuring Whisker Growth on Tin and Tin Alloy Surface Finishes. JESD22A121A" (JEDEC, Arlington, VA, 2008). 
43. G.R. Stafford, M.E. Williams, C.E. Johnson, K. Moon, U. Bertocci, O. Kongstein, W.J. Boettinger, ECS Trans. 1 (13), 71 (2006).

44. W.J. Boettinger, C.E. Johnson, L.A. Bendersky, K. Moon, M.E. Williams, G.R. Stafford, Acta Mater. 53 (19), 5033 (2005)

45. "Standards Set for Energy-Conserving LED Lighting" (National Institute of Standards and Technology, Gaithersburg, MD, 2008), www.nist.gov/pml/div685 /led_062408.cfm (accessed January 2012).

46. "Solid-state lighting metrology" (National Institute of Standards and Technology, Gaithersburg, MD, 2010), www.nist.gov/pml/div685/grp05/ssl.cfm (accessed January 2012).

47. Measurement of LEDs. CIE 127-2007 (Commission Internationale de L'Eclairage, Vienna, Austria, 2007).

48. Approved Method: Electrical and Photometric Measurements of Solid-State Lighting Products (Illuminating Engineering Society, New York, 2008).

49. Approved Method: Measuring Lumen Maintenance of LED Light Sources (Illuminating Engineering Society, New York, 2008).

50. American National Standard for Electric Lamps-Specifications for the Chromaticity of Solid State Lighting (SSL) Products (National Electrical Manufacturers Association, Rosslyn, VA, 2008).

51. "Color rendering of light sources" (National Institute of Standards and Technology, Gaithersburg, MD, 2010), www.nist.gov/pml/div685/grp05/vision_color.cfm (accessed January 2012).

52. ENERGY STAR Program Integrity Can Be Enhanced Through Expanded Product Testing (Report 10-P-0040, U.S. Environmental Protection Agency, Washington, DC, 2009)

53. Technology Roadmap: Solar Photovoltaic Energy (International Energy Agency, Paris, France, 2010).

54. "Electronic Structure and Excited-State Dynamics at Donor-Acceptor Interfaces" (National Institute of Standards and Technology, Gaithersburg, MD, 2010), www.nist.gov/mml/surface/excited_state_dynamics.cfm (accessed January 2012).
55. "Versailles Project on Advanced Materials and Standards (VAMAS), TWA 36 Organic Electronics" (VAMAS Secretariat, Gaithersburg, MD), www.vamas.org/ twa36/ (accessed January 2012).

56. "Candidate List of Substances of Very High Concern for Authorization" (European Chemicals Agency, Helsinki, Finland, 2011), echa.europa.eu/chem data/authorisation_process/candidate_list_table_en.asp (accessed January 2012). 57. "Directive 2011/65/EU of The European Parliament and of the Council of 8 June 2011 on the Restriction of the Use of Certain Hazardous Substances in Electrical and Electronic Equipment (Recast)," Off. J. Eur. Union L 174, 88 (2011).

58. T. Linsinger, A. Birgersson-Liebich, F. Pellizzato, T. Venelinov, S. Voorspoels, A. Lamberty, Certification Report: Certification of the mass fractions of various polybrominated diphenyl ethers (PBDES), decabrominated biphenyl and total $\mathrm{Br}$ and total $\mathrm{Sb}$ in two polymer reference materials. (Certified Reference Materials ERM@-EC590 \& ERM®-EC591 (Institute for Reference Materials and Measurements, Geel, Belgium, 2009).

59. "Support of Industry Compliance with the EU Directive on Restriction of Certain Hazardous Substances (RoHS)" (National Institute of Standards and Technology, Gaithersburg, MD, 2011),; www.nist.gov/mml/analytical/inorganic /rohs.cfm (accessed January 2012)

60. "Sustainability Standards Portal" (National Institute of Standards and Technology, Gaithersburg, MD, 2010), www.mel.nist.gov/msid/SSP (accessed January 2012).

61. S. Rachuri, P. Sarkar, A. Narayanan, J.H. Lee, P. Witherell, in Glocalized Solutions for Sustainability in Manufacturing: Proceedings of the 18th CIRP International Conference on Life Cycle Engineering, Technische Universität Braunschweig, Braunschweig, Germany, May 2nd-4th, 2011, J. Hesselbach, C. Herrmann, Eds. (Springer, New York, 2011), pp. 543-548.

62. "NIST Prototypes Framework for Evaluating Sustainability Standards" (National Institute of Standards and Technology, Gaithersburg, MD, 2011), www.nist.gov/el/msid/sustain-042611.cfm (accessed January 2012).

63. E.D. Simmon, J.V. Messina, paper presented at the IPC APEX Conference, Las Vegas, NV, 1-8 April 2008.

\begin{tabular}{|c|c|c|}
\hline 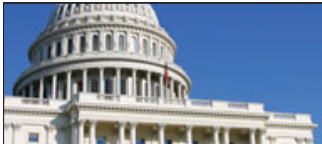 & 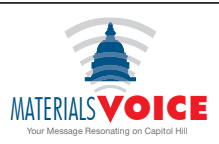 & $\begin{array}{l}\text { A Web-based tool to ensure that your voice } \\
\text { is heard on Capitol Hill } \\
\text { www.mrs.org/materialsvoice }\end{array}$ \\
\hline
\end{tabular}

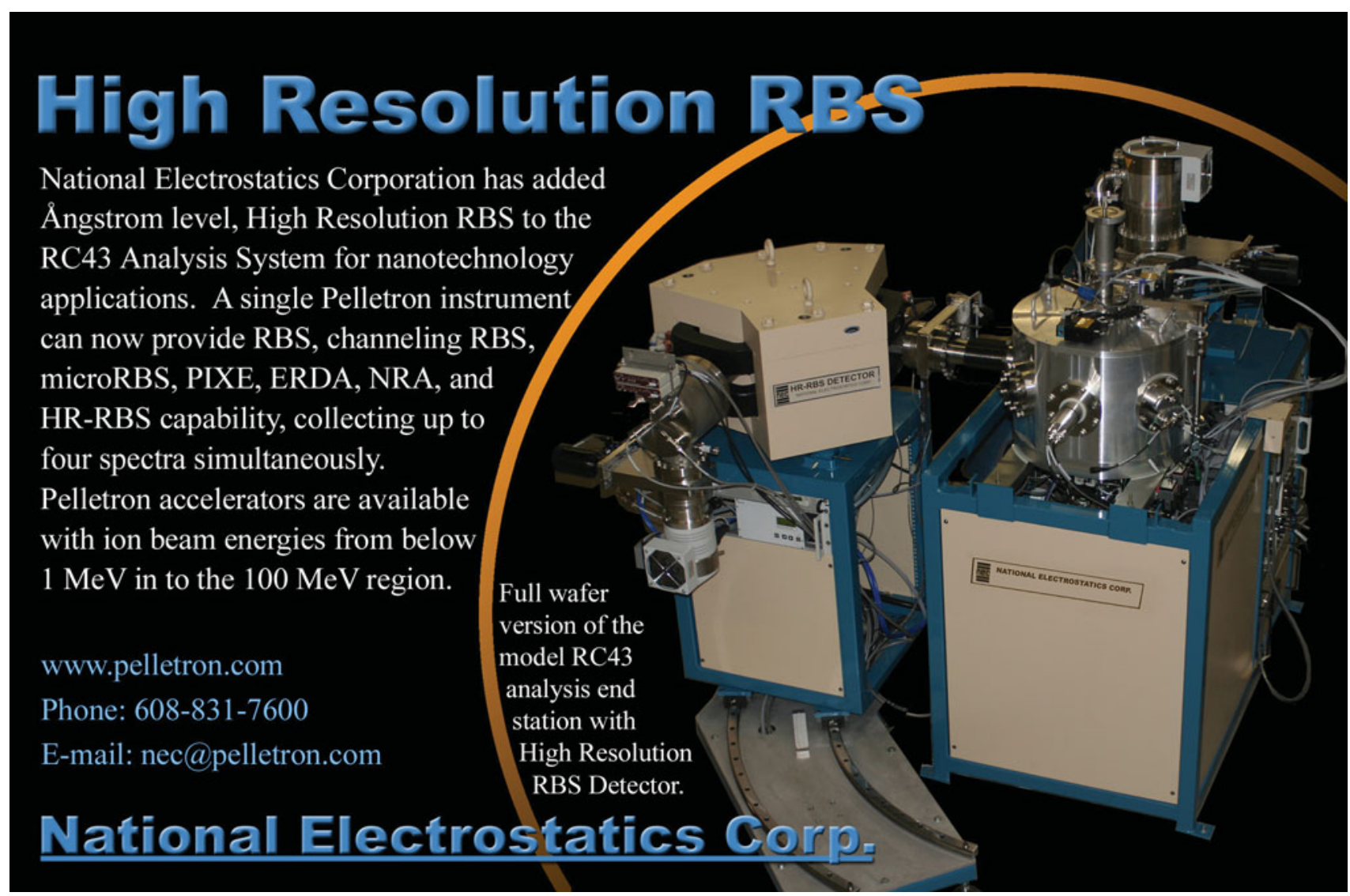

